\title{
INFRABONY POCKETS IN CHRONIC AND AGGRESSIVE PERIODONTITIS. A CONE BEAM STUDY
}

\author{
Shereen Abdel Moula* and Hussein I Saudi**
}

\begin{abstract}
The present research was conducted to explore the infra bony pockets in chronic and generalized aggressive periodontitis from the radiographic point of view using CBCT. A total of 150 infrabony pockets were included in the study obtained from 33 patients (20 females and 13 males). The defects were classified into 2 equal groups, 75 defects in chronic periodontitis (Group I), 75 in the generalized aggressive periodontitis (Group II). The Simplant program was used to measure the infrabony pocket depth, the vertical bone loss, the defect angulation, the bone density at the base of the defect, the defect volume. Also the percentage of furcation involvement and presence of calculus were recorded. Results showed higher rates of alveolar bone loss, wider defect angles, decreased bone density apical to the defects, larger defect volumes and more furcation involvement in Group II compared to Group I with statistically significant differences. On the other hand Group I showed significant percentage of calculus formation when compared to Group II. So it can be concluded that the multifactorial risk factors associated with generalized aggressive periodontics resulted in too much higher rates of periodontal destruction when compared to the chronic periodontitis group. Also the local factors play an important role in the pathogenesis of chronic periodontitis, but they are of little importance in generalized aggressive forms. The Simplant software technologies enabled measuring the defect volume which can aid in the estimation of the proper graft volume before surgery.
\end{abstract}

\section{INTRODUCTION}

Loss of alveolar bone support is one of the characteristic signs of destructive periodontal diseases and is generally considered to represent the anatomical sequel to the apical spread of periodontitis. The extent and the severity of alveolar bone loss in the dentition are usually assessed by a combination of radiographic and clinical means and are important adjuncts to the clinician in the diagnosis, treatment planning, and assessment of prognosis of the periodontal patient. The presence of periodontal osseous lesions is clinically significant in many ways. It relates to the associated loss of tooth support, to the site specificity of periodontal destruction, and disease progression ${ }^{1}$.

\footnotetext{
* Associate Professor of Oral Medicine, Periodontology, Diagnosis and Radiology, Faculty of Dentistry, Tanta University.

** Professor of Oral Medicine, Periodontology, Diagnosis and Radiology, Faculty of Dentistry ,Tanta University
} 
Aggressive periodontitis comprises a group of rapidly progressing forms of periodontal disease that occur in otherwise clinically healthy individuals. It is accepted that, compared with patients with chronic periodontitis, patients with aggressive periodontitis show a more rapid attachment loss and bone destruction that occurs earlier in life. The patient's age when attachment loss is detected is often the criterion used by clinicians to diagnose aggressive periodontitis and to distinguish aggressive periodontitis from chronic adult periodontitis ${ }^{2}$

The alveolar bone resorption should be detected by radiograph which includes periapical radiography, bitewing radiography and panoramic radiography. Periapical radiography is commonly used in clinical practice. Periodontal bone resorption, observed by periapical radiographs, is divided into vertical and horizontal bone resorption. Vertical resorption is characterized by the formation of intra bony defect observed during the surgery, which manifests as either a one-wall, two-wall or three-wall intrabony defect. Intrabony defects are three-dimensional (3D structures in the vertical, mesio-distal direction. However, periapical radiographs provide only and buccal-lingual a two-dimensional (2D) view, which cannot provide all the information about periodontal intrabony defects ${ }^{3}$.

So the aim of the present research is to explore the topography, dimensions and volume of the intrabony pockets in generalized aggressive and chronic periodontitis from the radiographic point of view for better understanding and to enhance the decision making for the treatment options.

\section{MATERIALS AND METHODS}

The present research was conducted in the Oral Medicine, Periodontology, Oral Diagnosis and Radiology Department, Faculty of Dentistry, Tanta University. The research was conducted on the patients came to the department seeking periodontal treatment. The research aimed to study the infrabony pockets in chronic and generalized aggressive periodontics from the radiographic point of view. The study included 150 infrabony pockets from 33 patients (20 females and 13 males). The patients were diagnosed whether being chronic or generalized aggressive periodontitis according to Caton et,al ${ }^{4}$ classification and criteria. The aim of the study was explained to the patients and signed informed consents according to the roles of the faculty Ethics Comity.

The 150 infrabony pockets represent 75 infrabony pockets from patient with chronic periodontitis group I while the other 75 represented the generalized aggressive periodontitis group II in mandibular molars. Cone beam radiographs were taken for all patients to evaluate their levels of bone loss. All of the cone beam slices and the 3D view were explored via the Simplant* 17.01software.

The following measurements were done for every infra bony pocket

\section{1- Infra bony Pocket depth}

The maximum infra bony pocket depth was calculated using "Measure Distance" tool in millimeters. A straight line was drawn at the level of the remaining marginal bone to the root, the maximum depth was drawn from the deepest base of the pocket to the horizontal line.

\section{2- Vertical bone loss}

The vertical bone loss was measured from the cemento enamel junction to the horizontal line extending from the marginal bone in millimeters Fig $(2,3)$.

\footnotetext{
* DENTSPLY Implants 3500 Hasselt Belgium
} 


\section{3- Total bone loss was gained from the sum of the} pocket depth and the vertical bone loss in millimeters.

\section{4- Pocket angle}

The angle between the bony aspect of the pocket and the straight tangent of the root was measured using the "Measure angle" tool in degrees.

\section{5- Pocket bone density}

The bone density at the base of the pocket was measured using the "Measure Density in Ellipse" tool in Hounsfield units (HU) Fig $(4,5)$.

\section{6- Pocket volume}

The 3D content of the 3D view was converted into 3D calculated object to facilitate the volume calculation process. The "Graft volume" tool was used to fill each pocket volume displaying the width, height and depth in millimeters in one panel and the total calculated volume in cubic centimeters in another Fig.(6-8).

\section{7- Furcation involvement}

The selected teeth were also examined for the presence of furcation involvement.

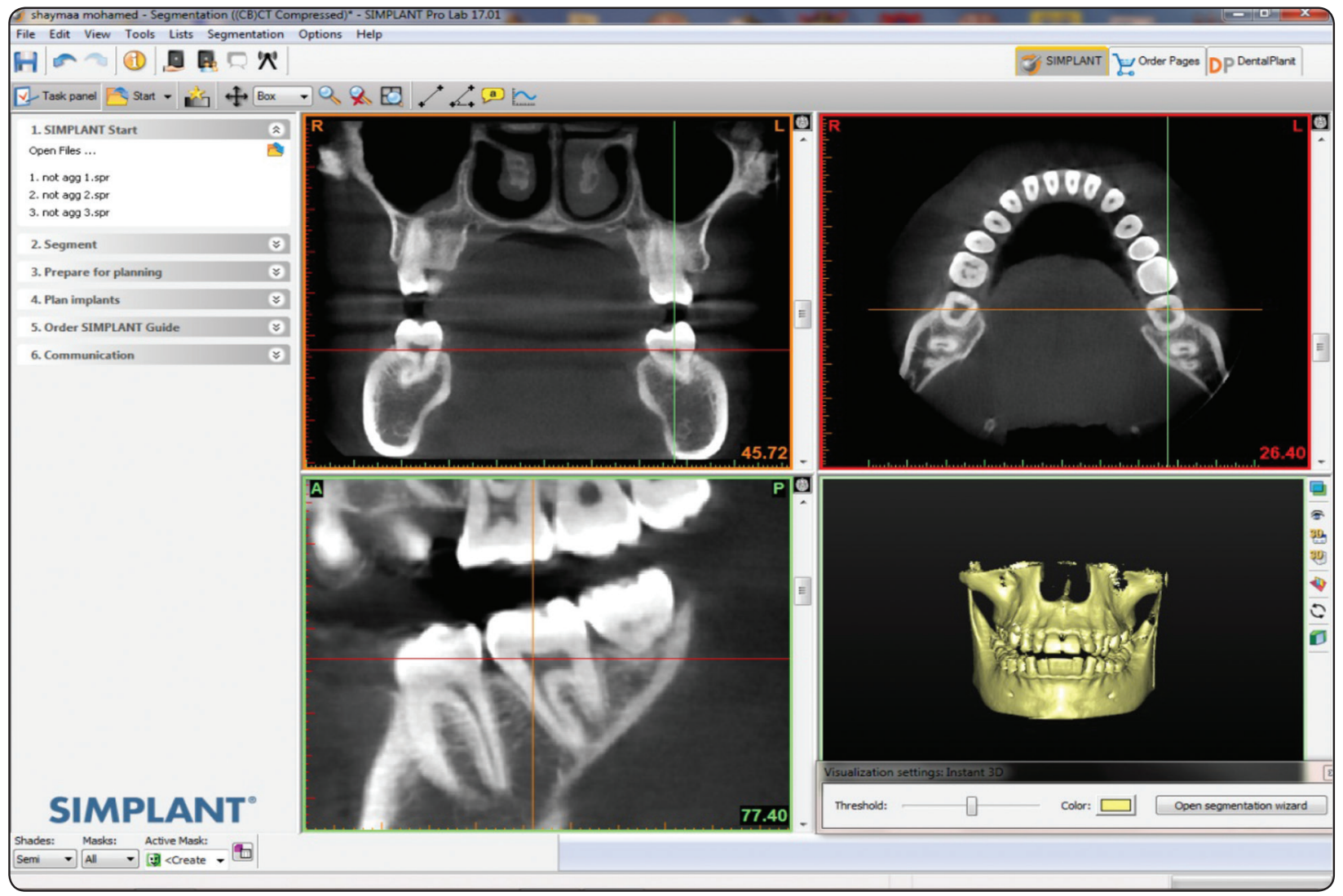

Fig (1) The Simplant program showing the coronal, axial, sagittal and 3D views. 


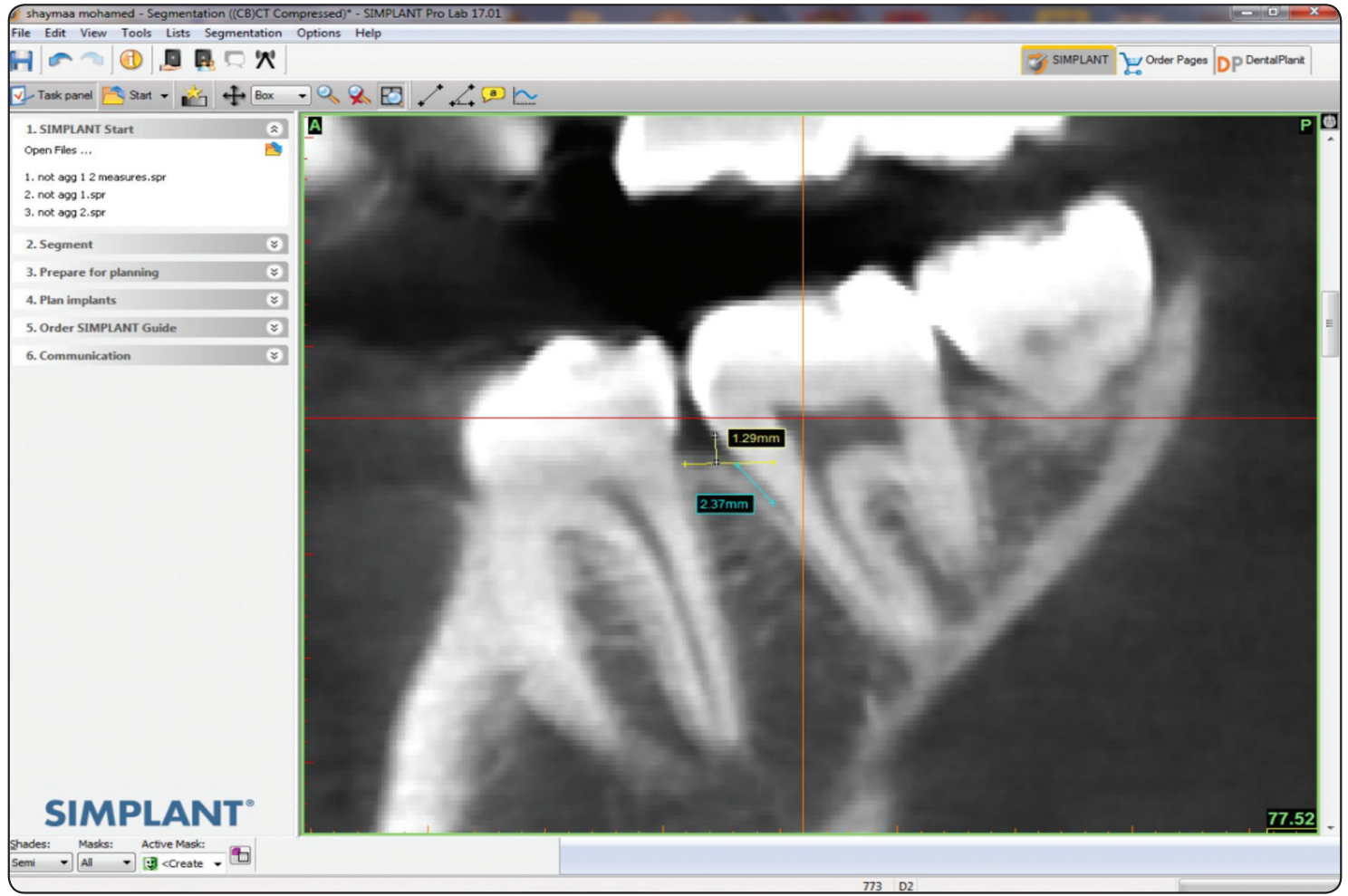

Fig (2) Showing infra bony pocket depth and vertical bone loss in a chronic periodontics case..

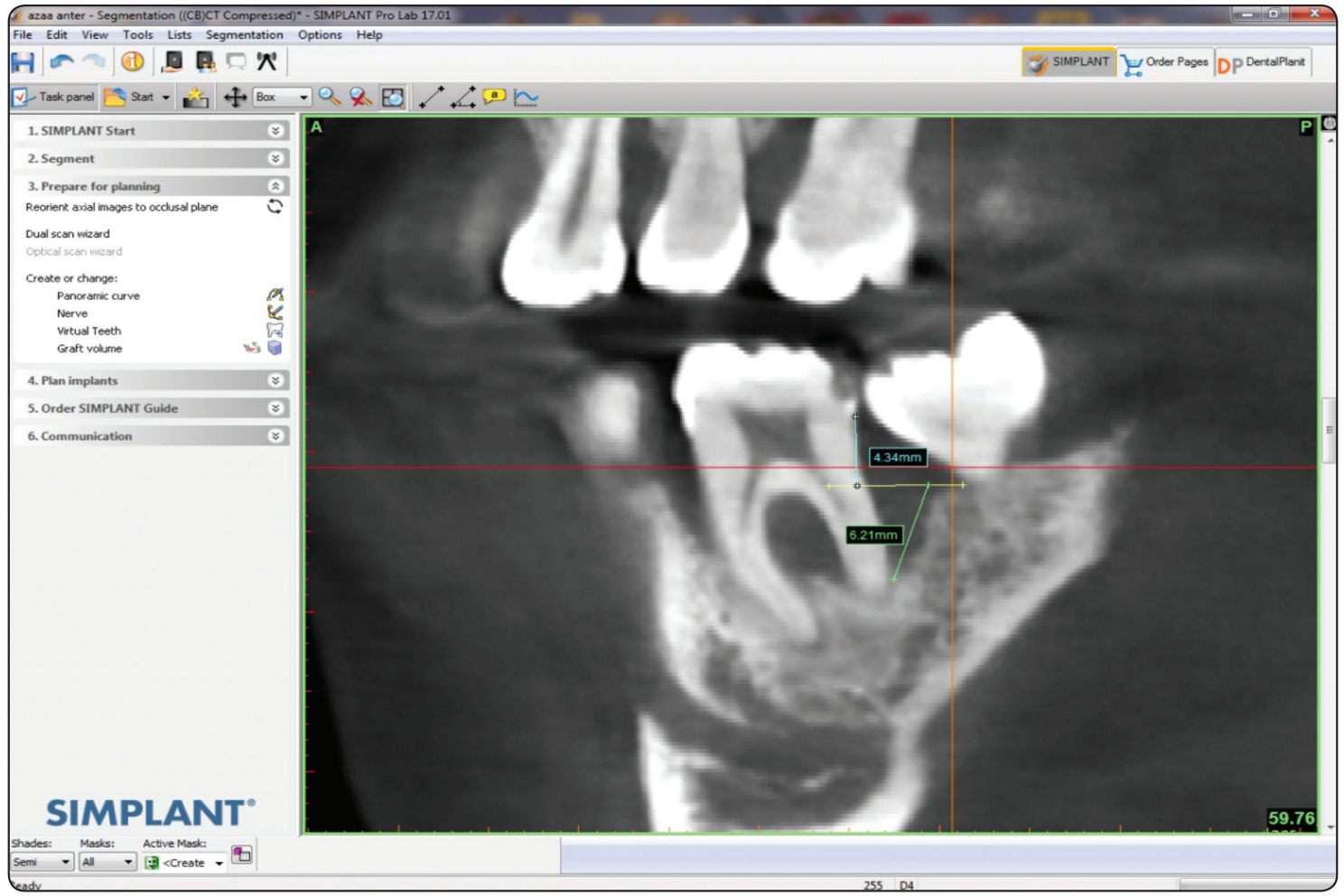

Fig (3) Showing infra bony pocket depth and vertical bone loss in generalized aggressive periodontitis. 


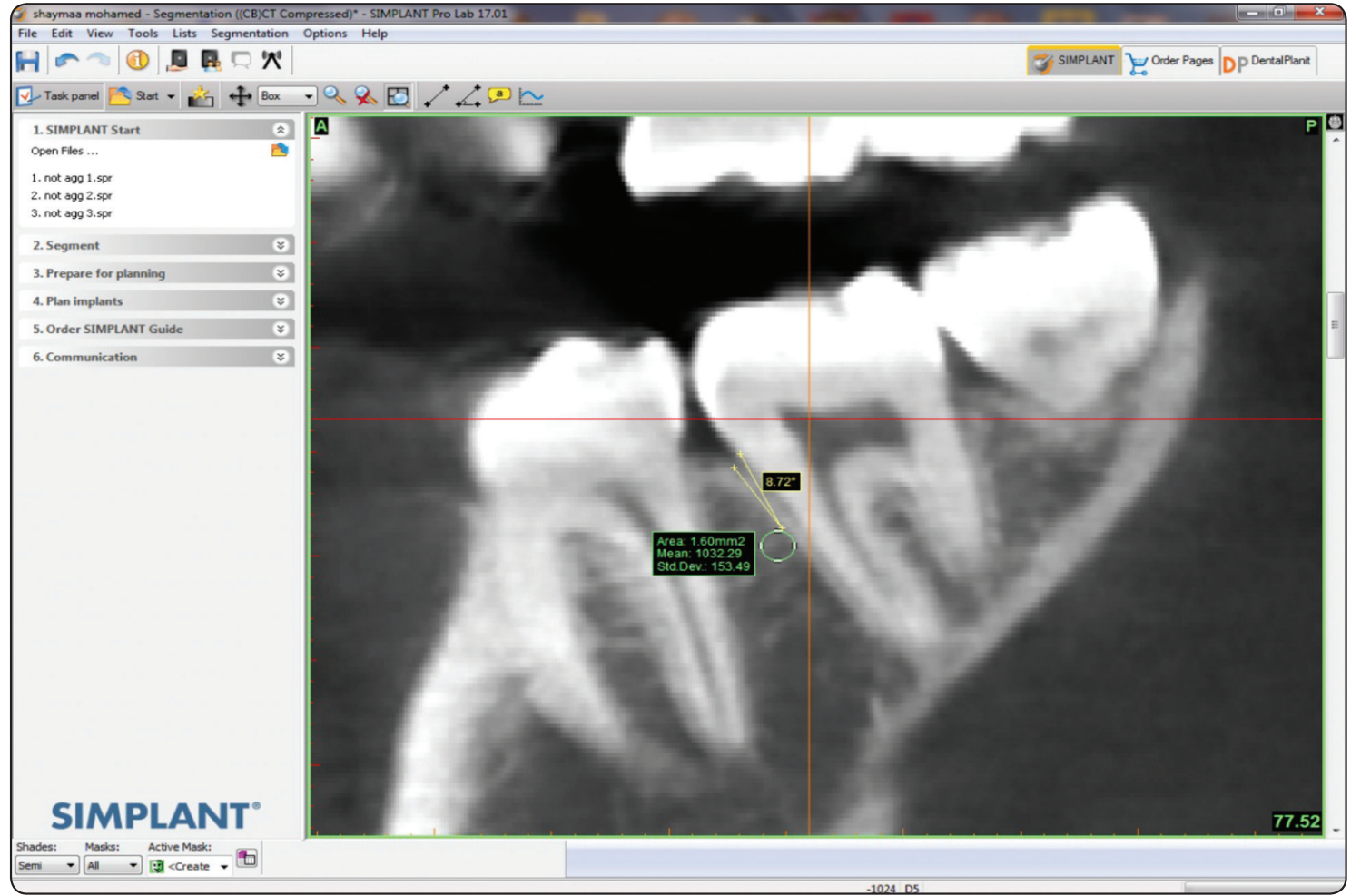

Fig (4) Showing pocket angle and pocket bone density in a chronic periodontitis case.

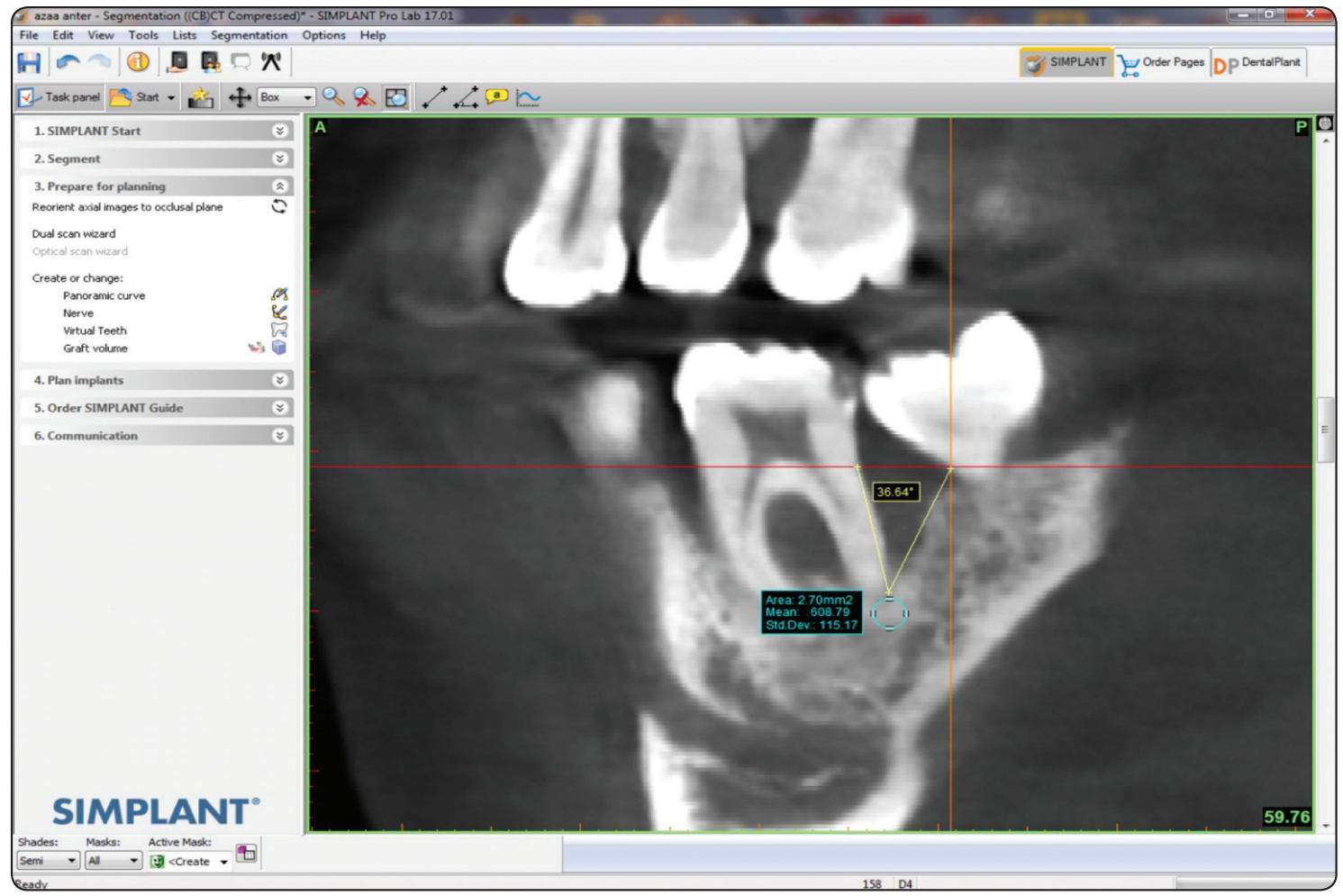

Fig (5) Showing pocket angle and pocket bone density in generalized aggressive periodontitis 


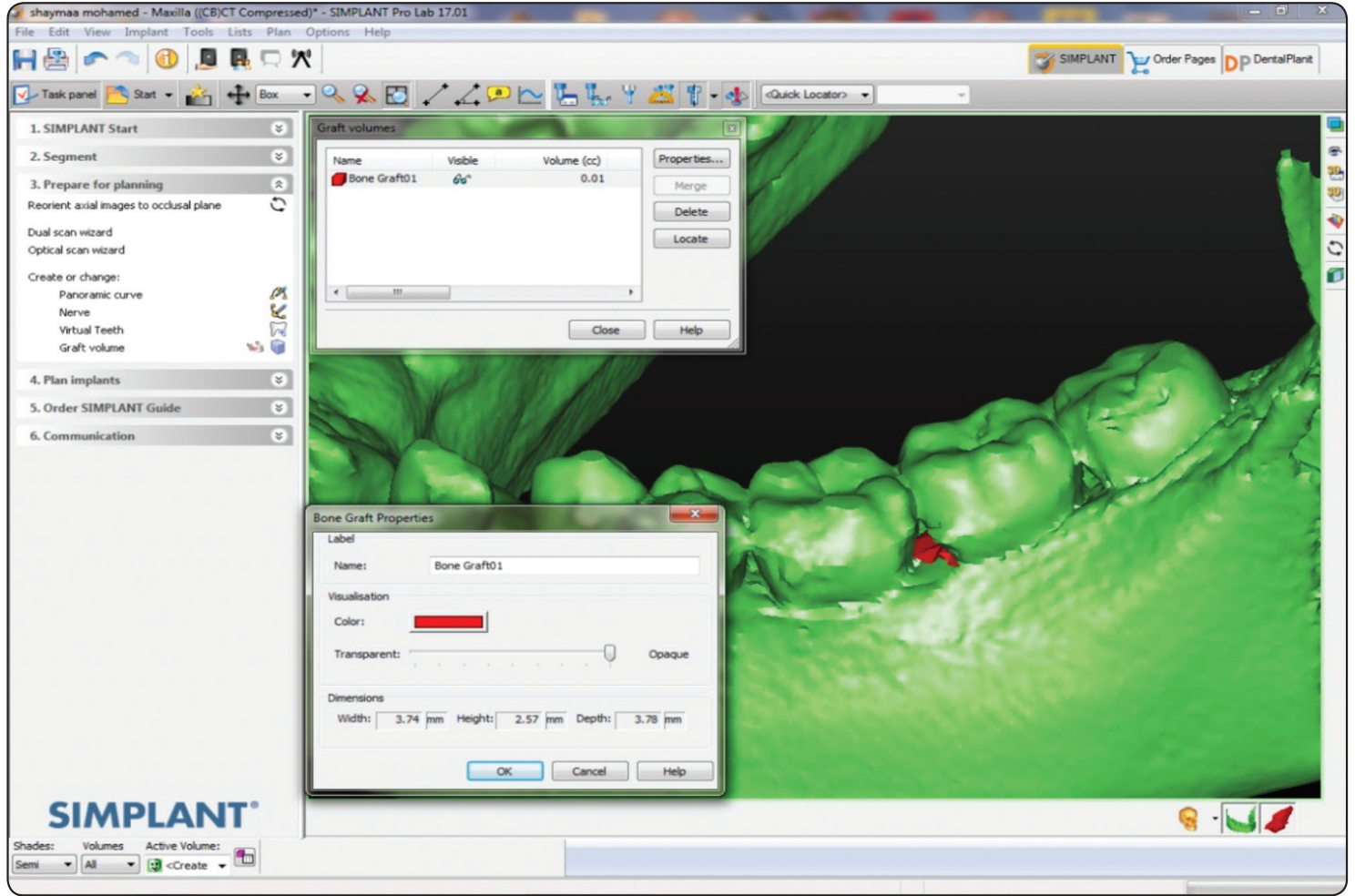

Fig (6) Showing infra bony pocket volume in a chronic periodontitis case

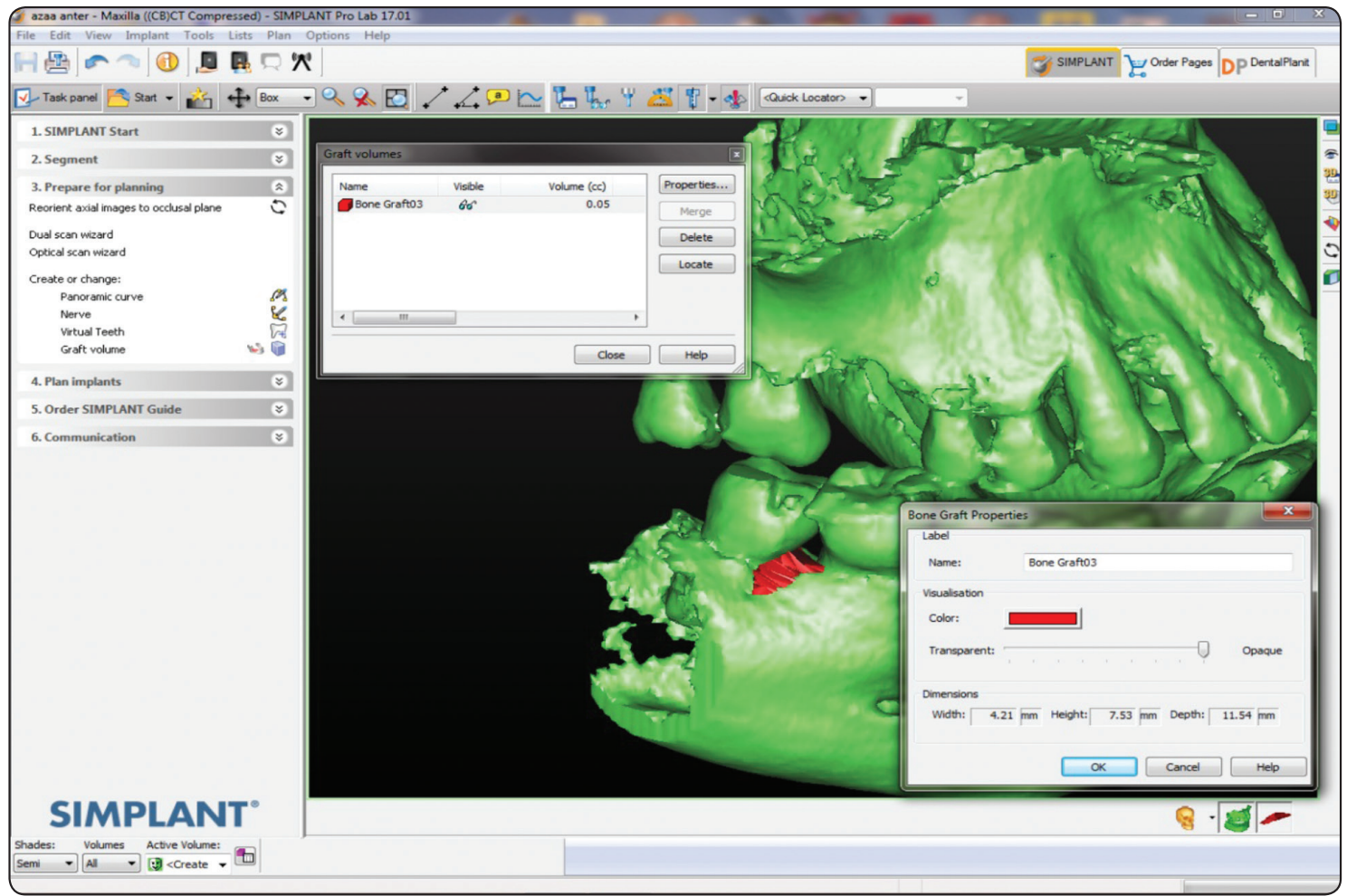

Fig (7) Showing infra bony pocket volume in generalized aggressive periodontics buccaly. 


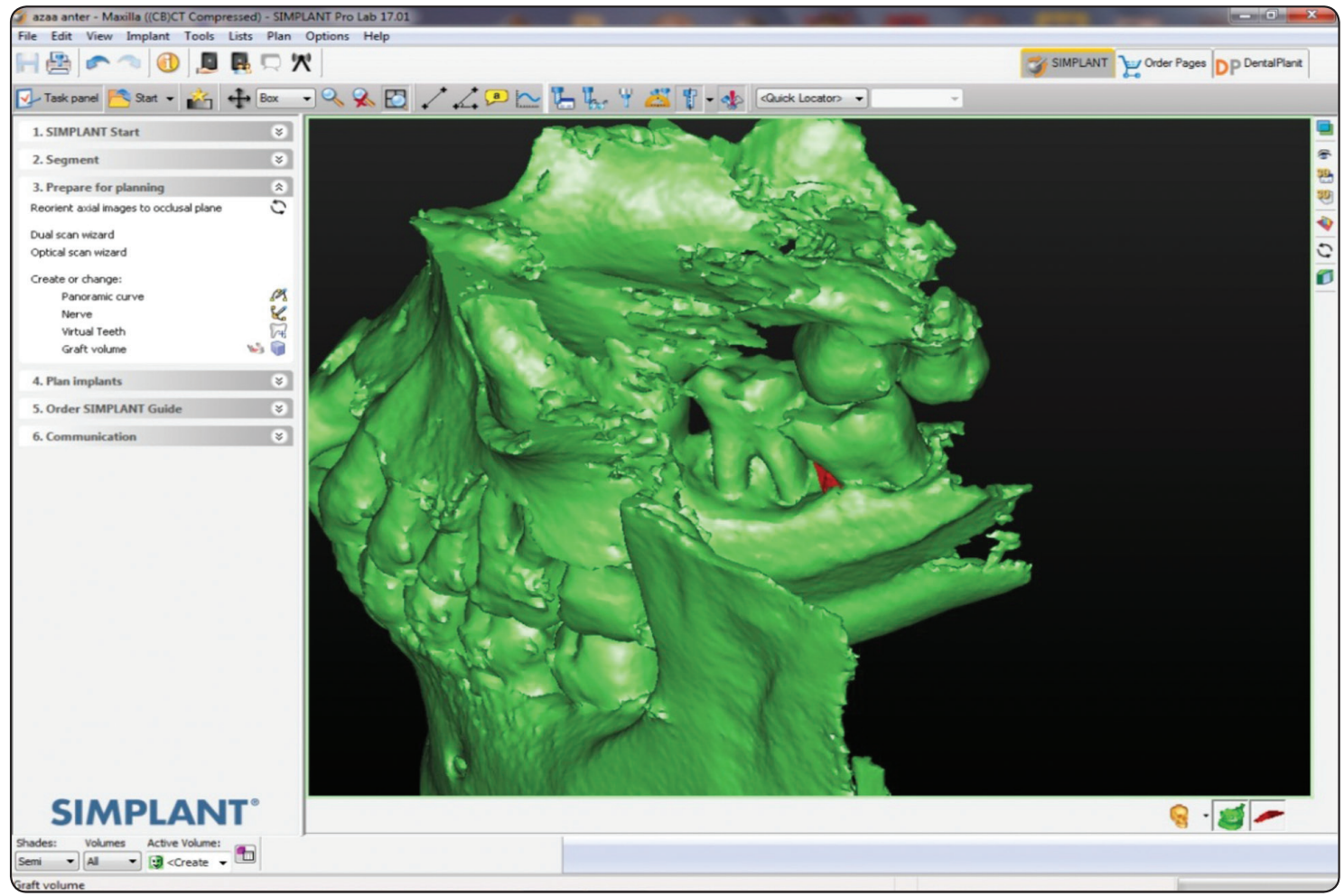

Fig (8) Showing infra bony pocket volume in generalized aggressive periodontics lingually..

\section{RESULTS}

The mean pocket depth in group I was $2.93 \pm 2.1$ millimeter compared to $6.48 \pm 1.89$ for group II with statistically significant differences $(\mathrm{p}<0.0001)$ for group II, the mean vertical bone loss was $1.77 \pm 2.45$ millimeter for group I compared to $5.13 \pm 2.18$ for group II with statistically significant differences $(\mathrm{p}<0.0001)$. Subsequently the mean total bone loss for group I was $4.70 \pm 2.21$ millimeter compared to $11.61 \pm 1.64$ in group II with statistically significant differences $(\mathrm{p}<0.0001)$. Moreover the mean pocket angle for group I was $8.93 \pm 3.51$ degree while it was $39.11 \pm 6.11$ in group II with statistically significant differences $(\mathrm{p}<0.0001)$

Also the mean pocket density at the pocket base was $591.41 \pm 33.16 \mathrm{HU}$ in group I but it was $678.39 \pm 47.36$ in group II with statistically significant differences $(\mathrm{p}<0.0001)$. The mean pocket volume in group I was $40.98 \pm 7.54$ cubic millimeter compared to $422.28 \pm 9.84$ for group II with statistically significant differences $(\mathrm{p}<0.0001)$. The furcation involvement represented $2 \%$ of the selected teeth compared to $23 \%$ for group II, while the presence of calculus represented $31 \%$ of the selected teeth compare to $4 \%$ in group II (Table 1, Graph 1). 
TABLE (1) Showing the recorded criteria for chronic periodontics (Group I) compared to the generalized aggressive periodontitis (Group II) using the two tailed student $t$ test ${ }^{* *}$.

\begin{tabular}{|c|c|c|c|c|}
\hline Parameters & Group1 & Group II & p & t \\
\hline Infra bony Pocket depth & $2.93 \pm 2.1$ & $6.48 \pm 1.89$ & $<0.0001$ & $10.88^{*}$ \\
\hline Vertical bone loss & $1.77 \pm 2.45$ & $5.13 \pm 2.18$ & $<0.0001$ & $8.87^{*}$ \\
\hline Total bone loss & $4.70 \pm 2.21$ & $11.61 \pm 1.64$ & $<0.0001$ & $21.74^{*}$ \\
\hline Pocket angle & $8.93 \pm 3.51$ & $39.11 \pm 6.11$ & $<0.0001$ & $37.09 *$ \\
\hline Pocket bone density & $591.41 \pm 33.16$ & $678.39 \pm 47.36$ & $<0.0001$ & $13.02^{*}$ \\
\hline Pocket volume & $40.98 \pm 7.54$ & $422.28 \pm 9.84$ & $<0.0001$ & $266.34^{*}$ \\
\hline Furcation involvement & $2 \%$ & $23 \%$ & & \\
\hline
\end{tabular}

*= Statistically significant at the 5\% level of significance.

** IBM SPSS Statistics 23 (IBM Corp.,Armonk, NY, USA

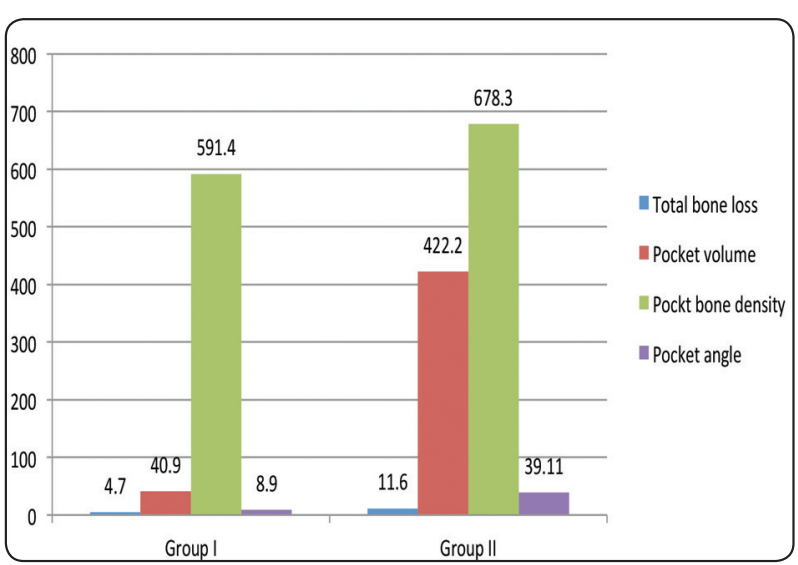

Graph (1) Showing the total vertical bone loss, pocket volume, pocket bone density and pocket angle in chronic periodontitis (Group I) and generalized aggressive periodontitis (Group II).

\section{DISCUSSION}

The present research was conducted to compare the chronic periodontics and generalized aggressive periodontitis from the radiographic point of view, mainly the infrabony pockets. The infra bony pockets were selected as the intraosseous lesions represent a clinical challenge for the periodontist as the sites with bone defects have been shown to be at higher risk of periodontitis progression in patients who had not received periodontal therapy ${ }^{5}$.
Exploring the hidden dimensions, topography and related bone density offers better therapeutic dimensions for such lesions. Moreover the exact measurements of the defect dimensions helped in surgical decision making. So the cone beam computed radiography (CBCT) was selected to investigate such defects as supported by Suphanantachat et $\mathrm{al}^{6}$, as they compared the intra oral radiography (IOR) and cone beam for evaluation of infrabony defect morphology and concluded that CBCT was superior to IOR for evaluation of infrabony defect morphology and provided excellent agreement among examiners on the assessment of infrabony defects ${ }^{6}$.

The infra bony pocket depth, the vertical height of bone loss and the subsequent total amount of bone loss in generalized aggressive periodontitis were statically significant when compared to chronic periodontitis. Such results agree with those of Schatzle et, $\mathrm{al}^{7}$ as they found that the amount of bone loss in aggressive periodontitis group was $0.19 \mathrm{~mm} /$ year compared to $0.05 \mathrm{~mm}$ /year for chronic periodontitis. Also Seidler et, $\mathrm{al}^{8}$ concluded that aggressive periodontitis, patients typically show a pronounced loss of periodontal attachment on multiple teeth compared to other forms of periodontitis. 
Moreover the fact that aggressive periodontitis produce more bone loss than chronic periodontitis was supported by Albandar ${ }^{9}$ who concluded that the distinction between aggressive periodontitis and chronic periodontitis is straightforward, particularly when adequate radiographic images reflect the extensive amount of bone loss in aggressive periodontitis.

Furthermore the results of the present research agree with those of Nibali et $\mathrm{al}^{10}$ who studied the radiographic morphology of intrabony defects in localized aggressive periodontitis compared to chronic periodontitis. Their measurements for the infrabony pocket depth was $3.43 \mathrm{~mm}$ and the vertical bone loss from CEJ to bone margin was 7.87 $\mathrm{mm}$ with total bone loss of $12.30 \mathrm{~mm}$ in aggressive periodontitis compared to $6.48 \mathrm{~mm}, 5.13 \mathrm{~mm}$ and $11.61 \mathrm{~mm}$ for the current study. However such differences may be attributed to the destructive pattern in generalized aggressive form and the localized form of periodontitis .Also their measurements were obtained from periapical radiographs compared to CBCT used in the current study.

The bone density at the base of the infrabony defect measured in HU was statistically significant higher in the generalized aggressive group when compared to the chronic periodontitis group. Also the mean volume of the infrabony pocket was much larger in generalized aggressive from when compared to the chronic periodontics group. Moreover the mean infrabony pocket defect angle was much wider in aggressive form compared to the chronic periodontitis. Furthermore the percentage of furcation involvement was higher in the aggressive form when compared to the chronic form of periodontitis. Such results may be attributed to the interplay of microbiologic, genetic, immunologic, and environmental risk factors with virulent pathogenic bacteria in the dental plaque especially Aggregatibacter actinomycetemcomitans and Porphyromonas gingivalis in aggressive forms ${ }^{11-16}$.
Although the percentage of calculus deposits was higher and statistically significant in the chronic periodontitis sites compared to the generalized aggressive periodontitis sites the amounts of vertical bone loss, defect angulation, bone density reduction and pocket volume were higher and statistically significant in the aggressive form when compared to the chronic periodontitis in the present research. Such results agree with many studies.

Albandar ${ }^{2}$ concluded that the amount of local etiologic factors is not commensurate with the severity of periodontal destruction. Gross deposits of dental calculus are uncommon in most cases of aggressive periodontitis, and in the early stages of the disease the gingiva has a normal clinical appearance with no clinical signs of gingival inflammation. Also Baer ${ }^{17}$ stated that in aggressive periodontitis there is a lack of a relationship between local etiologic factors and the amount of periodontal destruction. Moreover Seidler et $\mathrm{a}^{8}$. stated that in aggressive periodontitis the patients showed an insignificant amount of supragingival dental plaque or calculus on their teeth.

Based on the results obtained from the present study it can be concluded that the infrabony pockets in generalized aggressive periodontics had exaggerated dimensions and volumes compared to chronic periodontitis. Concerning the intrabony pocket volume to the best of our knowledge the present research is the mostly the first paper exploring the defect volume dimensions gained from CBCT using SIMPLANT 17.01 software. Estimating the volume of bone defects before surgery enables proper decision making for the flap design and the amount of needed bone grafts.

\section{REFERENCES}

1- Papapanou S. and Tonetti M. Diagnosis and epidemiology of periodontal osseous lesions. Periodontology 2000, Vol. $22,2000,8-21$.

2- Albandar JM. Global risk factors and risk indicators for periodontal diseases. Periodontol 2000 2002: 29: 177-206. 
3- Lestari A., Azhari, A. and Wendari S. The measurement of the alveolar bone crest in aggressive periodontitis using Cone Beam Computed Tomography imaging Padjadjaran Journal of Dentistry 2012;24(1):8-12.

4- Caton J,Armitage G, Berglundh T, et al. Anew classification scheme for periodontal and peri-implant diseases and conditions - Introduction and key changes from the 1999 classification. J Clin Periodontol. 2018;45(Suppl 20):S1S8. https://doi.org/10.1111/jcpe.12935

5- de Molon RS, Kim YJ, Dos Santos-Pinto A, Cirelli JA. Improvement of an anterior infrabone defect using combined periodontal and orthodontic therapy: A 6-year follow-up case report. Eur J Dent. 2014;8(3):407-11.

6- Suphanantachat S, Tantikul K, Tamsailom S, Kosalagood P, Nisapakultorn K, Tavedhikul K. Comparison of clinical values between cone beam computed tomography and conventional intraoral radiography in periodontal and infrabony defect assessment. Dentomaxillofac Radiol. 2017;46(6):20160461.

7- Schatzle M, Loe H, Lang NP, Heitz-Mayfield LJ, Burgin W, Anerud A, Boysen H. Clinical course of chronic periodontitis. III. Patterns, variations and risks of attachment loss. J Clin Periodontol 2003: 30: 909-918.

8- Seidler B, Miller SC, Wolf W. Systemic aspects of precocious advanced alveolar bone destruction; preliminary report. J Am Dent Assoc 1950: 40: 49-58, il

9- Albandar JM. Aggressive periodontitis: case definition and diagnostic criteria. Periodontol 2000 2014: 65: 13-26
10- Nibali, L \& Tomlins, P \& Akcalı, Aliye. Radiographic morphology of intrabony defects in the first molars of patients with localized aggressive periodontitis: Comparison with health and chronic periodontitis. Journal of Periodontal Research. 53. 2018.

11- Schache B. r, Baron F., Roßberg M., Wohlfeil M., Arndt R., and Eickholz P., "Aggregatibacter actinomycetemcomitans as indicator for aggressive periodontitis by two analysing strategies," Journal of Clinical Periodontology, vol. 34, no. 7, pp. 566-573, 2007.

12 Armitage G. C., "Comparison of the microbiological features of chronic and aggressive periodontitis," Periodontology 2000, vol. 53, no. 1, pp. 70-88, 2010.

13. Hørmand J, Frandsen A. Juvenile periodontitis. Localization of bone loss in relation to age, sex, and teeth. J Clin Periodontol 1979: 6: 407-416.

14. Gjermo P, Bellini HT, Pereira Santos V, Martins JG, Ferracyoli JR. Prevalence of bone loss in a group of Brazilian teenagers assessed on bite-wing radiographs. J Clin Periodontol 1984: 11: 104-113.

15. Gunsolley JC, Califano JV, Koertge TE, Burmeister JA, Cooper LC, Schenkein HA. Longitudinal assessment of early onset periodontitis. J Periodontol 1995: 66: 321-328.

16- Schatzle M, Lo“e H, Lang NP, Heitz-Mayfield LJ, Burgin W, Anerud A, Boysen H. Clinical course of chronic periodontitis. III. Patterns, variations and risks of attachment loss. J Clin Periodontol 2003: 30: 909-918.

17- Baer PN. The case for periodontosis as a clinical entity. J Periodontol 1971: 42: 516-520. 